LA-7696-MS

Informal Report

UC-37

Issued: February 1979

\title{
Calibration of Moisture Monitors
}

\author{
R. L. Gutierrez
}

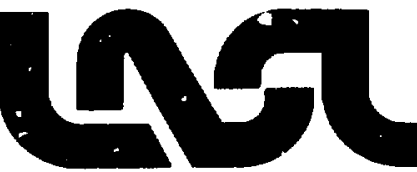




\title{
CALIBRATION OF MOISTURE MONITORS
}

by

R. L. Gutierrez

\begin{abstract}
A method for calibrating an aluminum oxide hygrometer against an optical chilled mirror dew-point hygrometer has been established. A theoretical crosspoint line of dew points from both hygrometers and a maximum moisture content of $10 \mathrm{ppm}_{\mathrm{v}}$ are used to define an area for calibrating the sensor probes of the aluminum oxide hygrometer.
\end{abstract}

\section{INTRODUCTION}

The purpose of this report is to establish a method for calibrating an anaiytical instrument used to monitor the moisture content of an inert atmosphere (argon or helium) inside a glovebox. Because of the hygroscopic nature of the material being processed in the glovebox, the inert atmosphere must be monitored on a continuous basis. The instrument used for this purpose is a Veekay Aluminum Oxide Hygrometer, Model 35S. The Veekay Hygrometer probes measure vapor pressure, which can be converted to a dew-point temperature. An EG\&G Optical Chilled Mirror Dew-Point Hygrometer, which provides a primary measurement of absolute humidity, ${ }^{1}$ is used to calibrate the Veekay Hygrometer.

\section{DISCUSSION}

To provide quality assured carbide fuel and insulator pellets that must meet a maximum specification requirement for oxygen, it has been determined from past technical experience that the moisture content of an inert atmosphere must be maintained at a level of $\leq 10 \mathrm{ppm}_{\mathrm{v}}$. Sensors are mounted inside each glovebox so that the inert atmosphere cari be monitored continuously. "These sensors are set 
to alarm a light above the glovebox whenever the $10 \mathrm{ppm}_{v}$ level is exceeded. They also provide a continuous reading on a millivolt meter that is proportional to moisture content of the gas sample. Each sensor comes with its own calibration curve. The millivolt output reading can be converted to vapor pressure of water, dew-point temperature, or moisture content on a parts per million basis using these curves.

The sensor consists of an aluminum strip which is anodized by a special process to provide a porous oxide layer. A thin coating of gold is evaporated over over this structure. The aluminum base and the gold layer form the two electrodes of what is essentially an aluminum oxide capacitor.

Water vapor is transported through the gold layer and equilibrates on the pore walls in a manner functionally related to the vapor pressure of the water in the atmosphere surrounding the sensor. The number of water molecules absorbed on the oxide structure determines the conductivity of the pore wall. Each value of pore wall resistance provides a distinct value of electrical impedance which, in turn, is a direct measure of water vapor pressure.

The vapor pressure of water can be related to the concentration of water in a gas by the equation

$$
\operatorname{ppm}_{V}=\frac{P_{H_{2} 0}}{P_{T}} \times 10^{6},
$$

where

$$
\begin{aligned}
& \text { ppm }=\text { parts per million by volume, } \\
& P_{H_{2} O}=\text { vapor pressure of water as measured by the hygrometer, and } \\
& P_{T}=\text { total pressure of the system. }
\end{aligned}
$$

The equation, derived by using Dalton's law of partial pressures and the ideal gas law, is useful in determining the concentration of water in gases from hygrometer measurements and total system pressure data.

Veekay Limited, the hygrometer supplier, provides a calibration curve with each probe (sensor). For convenience, a graduation of hygrometer reading vs $\mathrm{ppm}_{v}$ in gases at $1 \mathrm{~atm}$ is provided on each calibration curve. The atmospheric pressure at Los Alamos is $590 \mathrm{~mm} \mathrm{Hg}$. Therefore, each calibration curve must first be adjusted to provide the proper hygrometer reading vs $\mathrm{ppm}_{\mathrm{v}}$ at $590 \mathrm{~mm} \mathrm{Hg}$. These 
calculations were done using the above equation and the calculated data for vapor pressure of water, dew point, and $\mathrm{ppm}_{v}$ of water at $590 \mathrm{~mm} \mathrm{Hg}$ are iisted in Table I. Care must be taken to assure that whenever a new probe is used the $\mathrm{ppm}_{v}$ scale, on the calibration curve, be adjusted for atmospheric pressure at Los Alamos.

\section{II1. CALIBRATION OF THE ALUMINUM OXIDE PROBES}

An Optical Chilled Mirror Dew-Point Hygrometer (EG\&G) is used to calibrate the aluminum oxide probes. The optically controlled chilled mirror dew-point analyzer ${ }^{2}$ is the only continuous measuring instrument that provides a primary measurement of the absolute moisture content of a gas. It is surpassed in accuracy only by the NBS Gravimetric Train and the NBS calibrated two-pressure generator, neither of which is a continuous measuring instrument. The EG\&G Dew-Point Hygrometer is certified as a complete instrument against these NBS traceable standards. A certificate of traceability is provided with the instrument. The output of the EG\&G hygrometer is expressed as a dew-point temperature. Figure 1 shows how the two hygrometers are connected to a glovebox. The EG\&G Hygrometer is portable and disconnects from the glovebox when calibration is completed.

TABLE I

WATER CONCENTRATION $\left(\mathrm{pPm}_{v}\right)$ AT $590 \mathrm{~mm} \mathrm{Hg}$

Dew Point

$\left({ }^{\circ} \mathrm{C}\right)$

$-46.75$

$-48.6$

$-50.0$

$-51.9$

$-54.1$

$-55.5$

$-57.3$

$-59.4$

$-62.3$

$-63.2$

$-64.0$

$-64.9$

$-65.9$

$-67.2$

$-68.6$

$-70.6$

$-73.3$

$-77.6$

$-80.0$
Vapor Pressure

$-(\mathrm{mm} \mathrm{Hg})$

0.0442

0.0354

0.0295

0.0236

0.0177

0.0147

0.0118

0.0089

0.0059

0.0053

0.0047

0.0041

0.0035

0.0030

0.0024

0.0018

0.0012

0.0006

0.0004
$\mathrm{H}_{2} \mathrm{O}(\mathrm{ppm}{ })$

75

60

50

40

30

25

20

15

10

9

8

7

6

5

4

3

2

1

0.7 


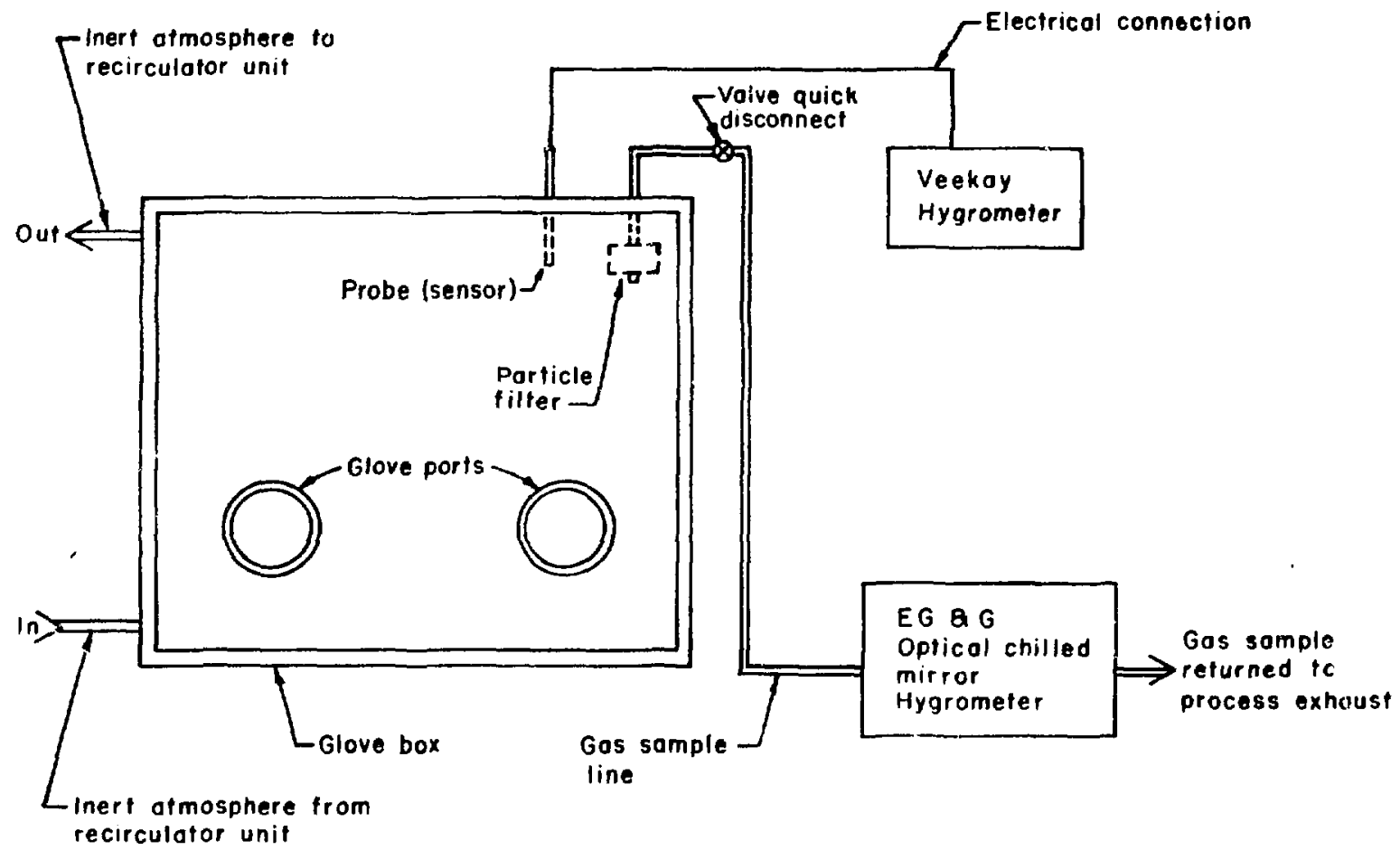

Fig. 1. Glovebox and hygrometers.

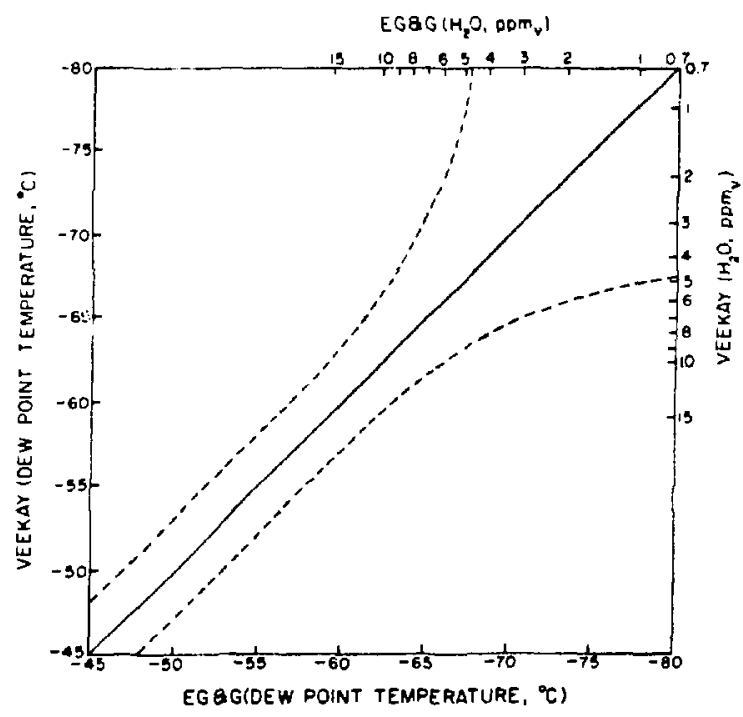

Fig. 2. Calibration curve for measured dew-point temperatures. 
As a method for calibrating a Veekay probe, Fig. 2 shows the dew-point temperatures for the Veekay hygrometer on the left vertical axis and dew-point temperatures for the EG\&G hygrometer on the bottom horizontal axis. The moisture content in $\mathrm{ppm}_{v}$ is represented by the right vertical axis for the Veekay hygrometer and the top horizontal axis for the EG\&G hygrometer. When a gas is sampled, the dew-point reading

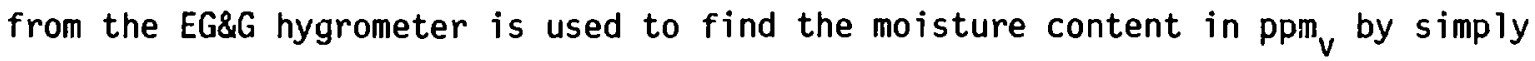
running a perpendicular line from the dew-point temperature reading on the bottom horizontal axis to the corresponding moisture reading on the top horizontal axis. The moisture content of the same gas sample, as measured by the Veekay hygrometer and attached probe, is found by using the Veekay digital reading to find either the moisture content in ppm $_{v}$ or the dew-point temperature by using the calibration curve supplied for that particular probe. Ideally, if the hygrometers were error free and produced accurate readings, the data from both instruments would produce a straight line curve 45 degrees to the horizontal axis as shown in Fig 2.

The hygrometers are not error free. The accuracy of the Veekay hygrometer ${ }^{3}$ is $\pm 3^{\circ} \mathrm{C}$ in the dew-point range $-66^{\circ} \mathrm{C}$ to $-110^{\circ} \mathrm{C}$. The accuracy of the EG\&G hygrometer is $\pm 0.139^{\circ} \mathrm{C}$ for the same range. Construction of an acceptable bandwidth about the ideal correlation relationship is required to permit calibration by comparison, taking into account the measurement errors of the two instruments.

At $-62^{\circ} \mathrm{C}$ or $10 \mathrm{ppm}_{v}$, the combined error in dew-point measurements results in an error in moisture concentration measurement of $\pm 4 \mathrm{ppm}_{v}$. Because of the logarithmic relationship between dew-point and moisture content or vapor pressure of water, this error diminishes to a value of less than \pm 1 ppm. The moisture content measurements made by each instrument on the same gas sample should agree within these ranges at these concentration levels. However, experience suggests that this degree of agreement is seldom realized and not essential for the purposes of process control. This is due in some measure to the inability to configure the two instrunents to measure exactly che same gas sample and to the dynamic character of the moisture content of the glovebox atmosphere during the course of the calibration. Accordingly, the acceptance band was arbitrarily broadened at low concentration levels as shown in Fig. 2.

Aluminum oxide probes certified within the operating band of Fig. 1 are sensitive enough to monitor and help control a moisture level in an inert atmosphere of $\leqq 10 \mathrm{ppm}_{v}$ so that carbide fuel pellets processed under these conditions contain $<250 \mathrm{ppm}$ of oxygen and 1 ppm of moisture. 
IV. CONCLUSION

A method for the calibration and certification of aluminum oxide hygrometer probes by comparing the moisture values obtained from the Veekay hygrometer and EG\&G hygrometer has been established. The calibration is performed on an inert gas sample where the moisture level is $\leqq 10 \mathrm{ppm}_{v}$ and done with the aid of a graph identifying an acceptable operating band for the aluminum oxide probes.

\section{REFERENCES}

1. Smithsonian Institution, "Hygrometric and Psychrometric Tables," Washington, D.C. (1976?).

2. EG\&G Application Data Sheets 3-050, 3-051, and 3-052, Environmental Equipment Division, Waltham, Massachusetts (1976).

3. Operation and Maintenance Manual, Veekay Hygrometer Model 35S, Veekay Limited, Concord, California (December 1975). 